\title{
The Evolution of Human Birth and Transhumanist Proposals of Enhancement
}

\author{
Eduardo R. Cruz \\ Pontifical Catholic University of São Paulo
}

\begin{abstract}
Some transhumanists argue that we must engage with theories and facts about our evolutionary past in order to promote future enhancements of the human body. At the same time, they call our attention to the flawed character of evolution and argue that there is a mismatch between adaptation to ancestral environments and contemporary life. One important trait of our evolutionary past which should not be ignored, and yet may hinder the continued perfection of humankind, is the peculiarly human way of bearing and raising children. The suffering associated with childbirth and a long childhood have demanded trade-offs that have enhanced our species, leading to cooperation, creativity, intelligence and resilience. Behaviors such as mother-infant engagement, empathy, storytelling and ritual have also helped to create what we value most in human beings. Therefore, the moral, cognitive and emotional enhancements proposed by these transhumanists may be impaired by their partial appropriation of evolution, insofar as the bittersweet experience of parenthood is left aside.
\end{abstract}

Keywords: transhumanism, evolution, emotions, parenthood, childbirth, natality

\section{Introduction}

In his "Letter to Mother Nature," leading transhumanist Max More says, "With all due respect, we must say that you [Mother Nature] have in many ways done a poor job with the human constitution ... We have decided that it is time to amend [it]." (More 2013 [1999], 449) He then lists seven recommended amendments, including mastery over our biological and neurological processes (i.e., to fix all defects in individuals and the species as a whole, leftovers from the process of evolution by natural selection) and the reshaping of our motivational patterns and emotional responses (Ibid., 450). This sentiment is echoed by Julian Savulescu and Anders Sandberg, also leading transhumanists, who have recently stated, "We need all the help we can get to liberate ourselves from evolution" $(2012,29)$. As I ponder these statements, two questions have emerged. First, is Mother Nature as careless as Max More supposes? Second, are her offspring truly doomed without drastic intervention?

Elsewhere, I have developed a rationale for the analysis of natality (in the sense conveyed by Hannah Arendt) in transhumanism. ${ }^{1}$ Here I will explore whether a defense of natality, in face of a future of designer babies, artificial wombs, or even a childfree society, can be based on an analysis of traits inherited by our biological past.

In order to accomplish this, and in a way answer the two questions above, we will 
first analyze the role that childbirth and childrearing had in human evolution. The second step takes into account that transhumanists do have emotions in mind in their concerns about the future. We will then argue that human emotions, in an evolutionary perspective, are closely related to birthing and rearing children, especially in three cases: mother-infant interaction, storytelling, and rites of passage. Finally, we will argue that directed evolution (Lewens [2013], 644, 647; cf. Askland [2011]), however feasible, cannot proceed by severing itself from our biological past, and this is especially true in the case of bringing new children into the world. Enhancements, in this case, exact a price that is higher than what most human beings would accept.

To achieve these goals we will not engage many of the critics of transhumanist ideas. In order to avoid certain biases in the literature, we have decided to follow our own sources more closely, spelled out in the next sections. In the first section, these sources are mainly writings from people who study biological and cultural evolution of our species, whereas in the next two transhumanist writings will be highlighted. Our argument will resort to many considerations of a more philosophical kind. Yet, we seek to remain close to data from evolutionary biology and correlated disciplines. As the literature on transhumanism is vast, we can only offer an overview of the issues.

"Transhumanism" is certainly an umbrella word, and many pro-enhancement researchers do not consider themselves part of the movement. At any rate, this study will engage in dialogue with these pro-enhancers with tenured positions in major universities across the globe. Such scholars usually have a more nuanced position regarding human enhancement than singulatarians and popularizer counterparts. Moreover, we will engage authors that are mainly concerned with biological enhancement, in different degrees of acceptance of human bodilyness.

\section{Human evolution and the role of new births}

This section intends to advance some elements for an answer to the two questions elicited by our reading of Max More. Narrowing them down, here we ask what the role is, if any, of new births and child rearing in human identity. After all, there are many men and women who are not parents, but are just as fully human as those who are. The same question applies to those who do not feel any urge to have children of their own.

Moreover, what does human evolution teach us about the parental role? Even if 
having children was adaptive in the past (after all, evolution is deeply connected with reproduction), it may not be necessary in the future, to the extent that it becomes possible to keep adults alive and well for as long as they wish. As we will see in more detail below, evolutionary psychologists speak about the mismatch between "the environment of evolutionary adaptedness" in the Pleistocene (Bjorklund and Pellegrini 2000) and the present Western industrial society. How much of this mismatch is a hindrance, however, is contended (Zuk 2013).

Childbirth, pain and pleasure, then and now

We all know that childbearing and childrearing among humans is more troublesome than it is for other species. Indeed, to bring a child to successful adulthood is as bittersweet an experience today, as it was in the Pleistocene, when our species arrived at its present form.

The focal point of this experience, especially for women, is the stage of pregancy, delivery and nurturing. This stage is marked by the "obstetric dilemma," a compromise that enables big-headed babies to pass through a narrow birth canal without jeopardizing the ability of women to follow the rest of their group closely on long journeys. Bipedalism (Trevathan [2010, 14, 85-86, 90-92]), the source of many human innovations, has significant drawbacks for females, specifically, the long, painful and dangerous process of delivery, which may harm both the mother and the newborn. Wells et al. $(2012,40)$ "question why natural selection should favor the persistence of an obstetric dilemma with such apparent adverse effects on either mother or offspring, or indeed both." The reason is that this adaptation provided beneficial traits (which will be explained below), not just adversity; the "evolutionary trade-offs" natural selection has provided include pleasurable aspects to childbirth on the biological, psychological, and social levels.

Anthropologist and evolutionary medicine expert Wenda Trevathan gives us a sound evolutionary basis for these trade-offs. For her, "the human body . . . is a bundle of 'compromises shaped by natural selection in small increments to maximize reproduction, not health.' This leaves us vulnerable to lots of diseases and disorders, but it also makes us amazingly resilient" (Trevathan 2010, 7). Perhaps it is this resilience that has made our species so successful, even more than other species.

Let us pause for a moment to tackle with the issue of pain. Experienced during 
childbirth, pain (both physical and emotional) raises a question about its evolutionary function of, apart from the obvious role of warning us of danger. There is a broad spectrum of literature on the matter (Bastian et.al. 2014; Leknes and Tracey 2008; Leknes and Tracey 2010; Maul 2007; Panksepp 2005, to name but a few). Most of these authors concur that pain is not only an evolutionary necessity, but that it also has a beneficial role. More importantly, the pursuit of pleasure and happiness is frustrated if one does not consider their evolutionary origins in conjunction with pain and suffering (Bastian et.al. 2014; Nesse 2004), especially because pain and pleasure share the same areas of the brain, albeit in different manners (Leknes and Tracey 2008; cf. Nesse [2004], 1340).

It seems that the old saying, "no pain, no gain," despite its simplistic ring, is now supported by evolutionary studies (De Prycker 2007; Leknes and Tracey 2008, 314; 2010, 330-31). This is the case for both for voluntary and involuntary pain. Bastian et al. (2014) argue that "A focus on minimizing or eradicating pain communicates to people that 'the good life is the pain-free life.' ${ }^{2}$ However, engaging with some pain may be an important pathway toward realizing a range of beneficial outcomes. Moreover, some of these outcomes may never be fully realized through a focus on pleasure alone" (Ibid., 271).

Returning now to the pain experienced during childbirth, we should attempt an answer to the question posed by Wells et al., stated above. Biostatistician Armand Maul argues that pain in childbirth has adaptive value (Maul, 2007, 403). If he is right, all the inconvenience related to a narrow birth canal and large-headed babies is combined with positive experiences (keeping in mind that these are diverse among women). Women need assistance during childbirth, as opposed to most other mammalian species (Trevathan 2010,94), so these experiences benefit all involved: the mother and father, the newborn, and the community. Anthropologist Sarah Hrdy speaks about the sensual experiences provoked by oxytocin and other hormones released at birth (Hrdy 2000, xiii- xiv, 137-39; 153-54; 536-38; 2009, 212-14), and shares her own experiences as well as others. Human birth is painful and dangerous indeed, but the need for evolutionary fitness provided plenty of positive byproducts, especially when cultural arrangements are added (Trevathan [2010], Karlsdottir et.al [2014] and Caffrey [2014]).

On the road to empathy 
Going beyond the moment of birth, what else we can say in terms of adaptation? One crucial emotion in humans is empathy. What is the relationship between the communal ways of having children and empathy? Once babies are born, they need to be fed, and the process of feeding infants strengthens social bonds. This is all the more true if we recall that all babies are born prematurely. As anthropologist Meredith Small remarks, "the human infant is born neurologically unfinished and unable to coordinate muscle movement. In a sense, the human baby is not isolated but is part of a physiologically and emotionally entwined dyad of infant and caregiver." (Small 1997, 47)

The mother- (or other caregiver) infant bond, and in particular mutual eye contact, seems to be hardwired in the baby's brain (Pinker 2014, 136). Trevathan seconds this perspective: "A newborn baby seems to be exquisitely attuned to the mother's face and eyes. This is not surprising, considering that visual communication is one of the hallmarks of primates" (Trevathan 2010, 114). Psychologist Kim Bard (2009) explains that recent studies push "primary intersubjectivity" to something like thirty million YBP, indicating again that it is hardwired in the brain. Another psychologist, Matt Rossano, argues that in the evolution of humans, increased opportunities for motherinfant joint engagement and the development of a complex social world are important for more sophisticated forms of cognition (Rossano 2010, 147).

Moreover, mother-infant eye contact is also linked to breastfeeding, which is important not only to strengthen emotional bonds, but also to enhance health for both (Trevathan 2010, 127-144; Pinker 2014, 136ff.). Summing up all these aspects, we may argue that positive emotions in humans arose with the need for maternal care (see also Grinde 2012, 41).

In addition to the mother herself, much needed support, as Trevathan indicates, "comes from others (especially grandmothers ...)" and this support, together with "shared child care are key to this strategy, and probably were at the base of the evolution of the family structure and extended kin network that characterizes humans and distinguishes us from most other mammalian species" (Trevathan 2010, 155). Indeed, the positive role of maternal grandmothers in our evolution has been the subject of many studies (Hawkes [2006]; Hrdy [2009], 241ff). Extended kin, and particularly the presence of females, support motherhood and is fundamental to human evolution within the framework of cooperation and concern for others (Hrdy 2000, 271 passim). Considering the rather difficult and painful process of human birth and the 
corresponding need for allomothers, ${ }^{3}$ it is easy to see how strong this form of cooperation is, suggesting that the corresponding empathy has deep evolutionary, biochemical, and neurological underpinnings.

We can (as has been done) correlate these cooperating impulses to love, that illdefined but crucial emotion. Love, for example, emerges from the mother-infant relationship, starting from early mammals all the way up to humans. However, Hrdy warns us that we should not speak about "maternal instincts" among humans, so strong is the power of culture. Nevertheless, any initial attachment may be increased as the mother cares for the infant's needs and creates a solid bond between the two (Hrdy 2000, 532-542). This "laboratory of love" is beneficial not only for the infant and the mother, but, as already mentioned, for the community as a whole.

Hrdy argues that, even if forming a bond with its mother is a kind of instinctive act for a baby, for the mother (or alloparent) it is a voluntary act. This decision is not without consequences. As we can draw from what was said in the preceding section, the mother-infant relationship brings much suffering in the form of abnegation and unconditional commitment. It is as close to agape as anything we experience despite the fact that some cultural images of maternal love, rightly criticized by feminists, are no longer tenable.

Part of what we call "love" involves empathy. Like Grinde (2012), mentioned above, neurobiologist Jean Decety argues that "Empathic helping behavior may have also evolved because of its contribution to genetic fitness, and an impulse to care for offspring is almost certainly genetically hardwired in humans as well as in other mammals," (Decety 2001, 41) emphasizing the biological basis of voluntary acts. Emphasizing what we have said before, the particular mode of empathy in humans has at its roots the communal experience of childbirth and rearing, in continuity with other mammals and hominids.

Going up in the scale of development, one day these children raised in a communal context turn into adolescents. Several scholars have indicated that, in evolutionary terms, youth and adolescence, as further steps in child development, have value in themselves and are not just the annoying interval between infancy and adulthood. According to the widely quoted psychologist David F. Bjorklund, the contemporary trend in education is to see children as little adults. However, he says, our slow development as a species and prolonged immaturity appear to have adaptive value (Bjorklund 2007, 6). Moreover, there is a kind of dialectic between childhood and 
adulthood, since some aspects of the playful character of the former are retained in the latter: "Adult Homo juvenalis retain some of the fantasy play they practiced as children and with it create realities that our ancestors could not have imagined" (Ibid., 226). As we will see in the last section, this trait of our evolution has an impact on how we evaluate transhumanism. Similarly, the evolutionary outlook for empathy is integral to the evaluation that we will undertake in the second and third sections.

\section{Raising kids in the village: storytelling and rituals}

Although we have described human evolution as essentially connected to childbearing and childrearing, little was sad about specific communal practices that may also have adaptive value. We will try to fill in the gap in this section. Let us start from an important feature related to the community of parents and children, storytelling. Enabled mainly through alloparenting, storytelling is essential in a communal context. Evolutionary psychologist Michelle Scalise Sugiyama suggests that storytelling may be linked to information-gathering, which is crucial for human survival in ancestral environments (Scalise Sugiyama 2001, 237; 2011), and narrative is an assurance that relevant information is properly handed down to the next generation.

Literary theorist Brian Boyd discusses the emotional side of storytelling: "Mothers and others provide a social entertainment system for infants, apparently because evolution has selected for both adults and children who can turn childhood dependency into mutual delight" (Boyd 2009, 98; see also Gottschall [2012] and Gansel [2012]). Philologist Katja Mellmann (2012) is skeptical of hasty proposals that link storytelling to adaptations, addressing specifically Scalise Sugiyama. Nevertheless, she still considers stories to be fundamental to our survival, byproducts of a number of biological substrates designed for other purposes.

A final feature present in most societies which connects one generation to the next is rites of passage (Alcorta and Sosis 2005; Rossano 2009). These rites combine negative and positive emotions and are adaptive. Rituals are closely connected to myth, reflecting an estrangement from the environment in need of proper resolution, which leads to the development of social bonds (Leistle 2006). Rossano argues that "Motherinfant joint engagement is, in fact, an early form of social ritual that presages later adult rituals" (Rossano 2010, 142). Trevathan and Paleoanthropologist Karen Rosenberg have also extensively studied birth rites across cultures. They argue that "One result of the anatomic changes in the pelvis and the associated changes in the ways in which human 
infants are born is that birth has been transformed from the solitary event that it is for most mammals into a social and cultural event, often marked by culturally specific rules and ritual behavior" (Rosenberg and Trevathan 2002, 1205-see also Trevathan and Mckenna 2003).

Looking at these traits, one can in addition build a case for the relationship between parental care and intelligence. As biological anthropologist John H. Relethford argues, in a way summarizing what has been said in this whole section:

The behavioral flexibility of mammals ties in with their pattern of reproduction. In general, the more a species relies on parental care, the more intelligent it is, and the more it relies on learning rather than instinct. Extensive parental care requires increased intelligence and the ability to learn new behaviors in order to provide maximum care for infants. The increased emphasis on learning requires, in turn, an extended period of growth during which the information needed for adult life is absorbed. Furthermore, the extension of childhood requires more extensive child care so that offspring are protected during the time they are completing their growth and learning. (Relethford 2010, 121)

In other words, "behavioral flexibility" pairs with a plastic brain, and the intelligence of the human brain, neo-cortex included, is indelibly connected with the way we are born, reared, and pass through adolescence (see also Keller, Poortinga, and Schölmerich 2002). It may come as a surprise to the non-specialist that extended parental care, as a partial result of the "obstetric dilemma," would have as a by-product increased intelligence in ontogenetic and phylogenetic terms. After all, childless people are no less intelligent than those who have children, but we are speaking about the species, not individuals.

As we will see below in more detail, evolutionary adaptations for humans are unique because of the strength of gene-culture coevolution, emphasizing the role of epigenesis ${ }^{4}$ (Bjorklund 2006; Keller, Poortinga and Schölmerich 2002; Hewlett and Boyette 2012). However, independent of being adaptive or by-products of earlier adaptations, behaviors associated with having and rearing children appear to be fundamental to any future evolution through enhancement. This view is contrasted to a common one among transhumanists: that having children and nurturing them may have had adaptive value in the past, but intelligence does not depend on this trait anymore, so children are not intrinsically necessary to the future evolution of humankind.

Much of what is at stake in this paper hinges on this issue. Before advancing the argument, however, let us see how some representative transhumanists deals with the outcomes of human evolution. 


\section{Transhumanists and the evolution of birth}

As we have seen in the Introduction, Max More, in his "Letter to Mother Nature" deems evolution to be basically flawed, as far as human beings are concerned. It is up to us, therefore, to remake perfection in our own image and by our own design. If the amendments proposed by More take place, new generations will not be strictly necessary for human enhancement, and having children will be a matter of sheer whim.

In order to better understand what is at stake in this comment on More's viewpoint, this section will first present some transhumanists' perspectives on the wisdom of evolution (or lack thereof) and proposals for synthetic biology; their perspectives on the painful way by which human reproduction takes place and future proposals for infants and mothers; and on the role of negative emotions and pain. In a second step, we will see how transhumanists react or not to aspects from evolutionary past regarding human procreation, as described in the first section. Finally, we will have word about the issue of the permanence of personal identity, an important topic in transhumanist thought.

\section{Enhancement, synthetic biology, and our evolutionary past}

Can reproduction and enhancement of human traits (e.g., emotions) occur without regard to prior evolution? Even though most transhumanists are concerned only with future, directed evolution, a few respond in the affirmative and engage evolutionary studies in more depth. ${ }^{5}$ We will start a survey of some of these responses with Nick Bostrom and Sandberg (2008), who offer us a somewhat detailed study of the evolution of the brain.

They acknowledge the "wisdom of nature" (evolutionary optimality) behind evolution, but only to the extent that it points to its own overcoming. Bostrom and Sandberg end up with a somewhat dismal view of the processes of nature. According to these authors, "Even if evolution had managed to build the finest reproduction-andsurvival machine imaginable, we may still have reason to change it because what we value is not primarily to be maximally effective inclusive-fitness optimizers" (Ibid., 379). They not only see a mismatch between evolutionary processes and "what we value," but also see another mismatch between ancestral optimal conditions and the modern environment as something negative, detrimental to survival in contemporary 
society.

One of the most cited examples of this mismatch is sugar dependence. Once useful under the harsh conditions of hunter-gatherer ways of life, today it only leads to weight problems, diabetes, and so on. However, sugar addiction is a somewhat mechanical, straightforward and controllable trait. Earp et al. $(2014,5)$ also mention fight-or-flight reactions and antiparasite immune cells, which may not be as easily controlled.

Russell Powell and Allen Buchanan agree to some extent with this, but they are even more critical of evolution: "The ubiquity of suboptimal design demonstrates that natural selection is a bricoleur, not an engineer, much less a master engineer" (Powell and Buchanan 2011, 10). Then, moving from the past to the future, they say, "By highlighting the constraints on ordinary unassisted evolution, we show how intentional genetic modification can overcome many of the natural impediments to the human good" (Ibid. 6). Powell and Buchanan argue against Bostrom and Sandberg for their use, even partial, of the metaphor of the "wisdom of nature" and their resort to adaptationist explanations. Instead, they focus on more elementary mechanisms for evolution. According to Powell and Buchanan, basic molecular mechanisms would allow for intentional genetic bricolage (synthetic biology). Before proceeding to the question of motherhood, however, this form of assisted evolution deserves a few remarks of our own.

In the case of synthetic biology, the goal is not to amend (manipulate) an organism with a certain quantity of altered characteristics, but to rebuild it (Douglas and Savulescu [2010], 687; see also Powell, Kahane and Savulescu [2012]). Is this a hasslefree process? Ethicist Immaculada de Melo-Martín says something that is valid for both genetic and molecular manipulation: "those who oppose genetic enhancement technologies, and those who welcome them, have an inadequate understanding of human biology. First, both groups hold incorrect presuppositions about the role of genes in the development of human traits and behaviors, and both ignore the relevance of our social environment as a causal contributor to judgments about such traits" (de MeloMartín 2008, 198).

Moreover, Maarten Boudry and Massimo Pigliucci (2013) criticize the use of analogies from engineering: "Organisms are a product of historical processes that resulted in far more messy and less transparent systems than man-made machines," but at the same time this is the strength of natural selection: "The adage that "evolution is 
cleverer than you are,' . . . may also be good advice to synthetic biologists" (Ibid., 666). Powell, Kahane, and Savulescu (2012) would agree with the first part of the argument, but not with the latter. They criticize the "genetic blueprint metaphor" (that only genes matter) and emphasize the importance of context (Ibid., 454). Nevertheless, their description of the limits of genetic engineering does not preclude the optimism about future enhancements: "Eventually, the human species will be in a position to assume substantial and deliberate control over its own evolutionary biological destiny, taking decisions that could affect the fate of human nature, the human species, and the future life on Earth" (Ibid., 457). It remains to be seen if this optimism is tenable in the absence of a consensus around the "the wisdom of nature" (or "cleverer than you are") issue.

The reference to the context reminds one of the gene-culture coevolution (cf. our brief discussion of epigenesis above). In emphasizing tinkering at the genetic or molecular level, transhumanists may overlook its importance. There are a few references to coevolution in the transhumanist literature, but with no overall impact in the directed evolution discourse. Powell (2012) is an exception, although he spares just more than one page to spell out coevolution. Powell, Guy Kahane, and Savulescu (2012) highlight the importance of the environment to evolution, but they do so only as a warning, without references of how coevolution could be put to good use in enhancements.

\section{Enhancement and (which?) motherhood}

Heaving describe the issue of human evolution in general, let us now come closer to our object of study, motherhood. As we have seen, in motherhood negative and positive emotions are heightened and closely intertwined, thus being a good test case for possibilities of emotional enhancement.

Transhumanists remind us, quite rightly, that "Mother Nature" was not very kind to mothers, due to the difficult compromise between babies' big brains and their means of coming into the world. According to Powell and Buchanan, "the birth canal, which passes through the female pelvis thanks to selection's hasty rearrangement of hominid posture, dramatically increas[es] the risks of childbirth. The list [of unfavorable traits] goes on and on" (Powell and Buchanan 2011, 10). We see that there is no mention of trade-offs here. AI expert Bruce F. Katz $(2008,45)$ also points out the downside of large 
brains: the birthing process is painful and dangerous; babies are born prematurely; there is an increased dependency on parents; and babies have big and fragile skulls (Ibid., 356-57).

If evolution has done a poor job, then various technological solutions to this problem have been forwarded, in addition to the use of extra-uterine environments. One solution, which can leave the birthing process mostly untouched, is to have "designer babies," that is, to extend existing technologies of IVF to help to pave the way to posthumanity (Young 2006). There are more nuanced proposals, such as the "Procreativity Beneficence," of Savulescu and Kahane (2009): "If couples (or single reproducers) have decided to have a child, and selection is possible, then they have a significant moral reason to select the child, of the possible children they could have" (Ibid., 274).

Even more radically, for some, even "designer babies" will not be necessary, since there will be more efficient ways to produce posthumans. "The 'designer baby' revolution is going to be a very slow one; it won't be a significant factor in this century. Other revolutions will overtake it. . . The idea of designer babies . . . is just the reprogramming of the information processes in biology. But it's still biology, with all its profound limitations" (Kurzweil 2005, 225-26).

Whatever the method, for transhumanists, the yielding of new generations seems to follow the rational control endorsed by the technological and medical establishments. The issue of procreation gains even more importance when we consider the gendered nature of human bodies. Since they are predominantly males and unmarried (Pelissier and Dal Santo 2012, 23-24), transhumanists generally tend (unconsciously) to take the male body and modes of rationality as normative when thinking of enhancement (James Hughes [2010], Thomas Douglas et.al.[2010], and Guy Kahane and Julian Savulescu [2010]). On the road to "postgenderism," some authors (such as Dvorski and Hughes 2008), are somewhat condescending toward women, downgrading all that has to do with motherhood. Transhumanists explicitly favor a post-gender ideal, and the blurring of sexual identities: "It is only a matter of time before enhancement technologies allow people to be both male and female, or neither. So sex will become a matter of personal choice" (Kahane and Savulescu 2010, 22). Motherhood, in this context, seems to be too restrictive a choice. 
Though they do not have a high regard for motherhood, it is clear that transhumanists do care about emotions, either because humans are emotional beings and emotions are important in the pursuit of happiness or because they know that cognition is embodied and emotions are deeply intertwined with the body. As childbearing and childrearing are so integral to human emotions, it is certainly important to know what some transhumanists have to say about them.

Not many transhumanists engage in any sustained reflection about the origin of emotions. Instead, they simply point out that to enhance positive emotions is one of their goals. Bostrom, among those with a more academic standing, offers us glimpses of how to deal with emotions in order to reach enhancement and how positive emotions should be enhanced as well.

For example, he and Rebecca Roache assert that "experiencing undesirable states can improve our understanding of ourselves and others, and give our personalities a richness and depth that they might lack were we only ever to experience 'positive' emotions." (Bostrom and Roache 2008) Nonetheless, they are sure that it is possible to distinguish unpleasant emotions from pleasant ones, so "we may seek to reduce feelings of hate, contempt, or aggression when we consciously recognize that these feelings are prejudiced or unconstructive" (Ibid.; cf. Spezio [2011], 146 and Baylis [2009], 171).

Bostrom acknowledges that the proposed improvements are difficult: "It is considerably more difficult to characterize what would count as emotional enhancement" (Bostrom 2008, 119). Despite provisos like this, the general tenor is still the replacement of negative for positive emotions. We can infer from the context that the focus is mostly on the individual, as if emotions can improve only through personal enhancement: "Therapy, and indeed a program for individual mood enhancement, might usefully be directed at building up minds associated with positive emotions helping them to gain strength and to become elaborated" (Hope 2011, 241). The goal is "a maximum of possible excellence of emotional capacity" (Bostrom 2008, 119), including some unforeseen traits that would be enabled by newly devised neurological machinery.

In the transhumanist literature, unnecessary and involuntary suffering is generally viewed as senseless, yet another of the burdens inherited through the evolutionary process. Transhumanists do not spare words in describing the haphazard nature of evolution as a source of unimaginable suffering (Powell and Buchanan 2011, 18). The reaction against this state of affairs is equally strong: "I find it impossible to blindly 
accept the suffering imposed upon us by our biological condition" (Young 2006, position 91).

What is valid for suffering also applies for the twin concepts of pain/pleasure and sadness/happiness. As for happiness, transhumanist Michael LaTorra describes a general feeling: "Transhumanism is the opportunity to transform life, liberty, and the pursuit of happiness beyond current human limits" (LaTorra 2011, 210). More academic authors invoke a different goal than "the pursuit of happiness," such as "wellbeing,"(Bostrom and Savulescu) virtue (Hughes), "what we value," (Bostrom and human desires and intentions (Powell), thus confronting hedonist radicals such as David Pearce.

\section{Lessons from our evolutionary past}

Here we argue that the negative assessment of evolutionary processes by transhumanists results in birth and infancy being treated as unimportant in their writings. After reflecting a little on transhumanists' views about synthetic biology, varieties of motherhood and the role of pain, we may go back to some considerations of the first section of this paper and ask how they relate to transhumanist ideas. A panoramic view of the transhumanist literature, which includes articles in the Journal of Evolution and Technology (www.jetpress.org), seems to reveal little discussion on subjects such as the following ones:

- the simultaneous occurrence of pain and pleasure in childbirth

- the "no pain, no gain" principle

- the flow of hormones in the mother-child dyad

- the "village effect" for coping with the hardships of bearing and rearing children

- the effects of adolescence, storytelling, and rites of passage leading to increased intelligence and creativity.

It is not our purpose to engage on each subject at length, just to highlight a few issues more relevant to the present argument. For example, even though transhumanists argue that empathy can be enhanced through a variety of rationally controlled means, not much is said about the growth of empathy as a result of the human way of procreating, and the relation of empathy to love is seldom characterized. The work of Savulescu and colleagues is a notable exception to a description of love (Savulescu and Sandberg 
[2008], [2012]; Earp, Sandberg and Savulescu [2014]).

According to these writers, the evolutionary origins of love contribute to its own enhancement. From this perspective, "Underlying human love [there] is a set of basic brain systems for lust, romantic attraction and attachment that have evolved among mammals." (Savulescu and Sandberg 2008, 35) But evolution also harms love in our current context since it "can interfere with marital bliss in three main ways: through conferring different goals on men and women, through evolving relationship structures that promote inclusive fitness rather than happiness, and by way of a mismatch between current possibilities (e.g. lifespan) and evolved adaptations" (Ibid., 32-33). When speaking about the enhancement of marriage, Earp, Sandberg and Savulescu (2012) show a deep concern for the children of couples who have divorced. However, because of these authors' disturbance in the face of natural selection, they do not seem to acknowledge the role of childrearing in human evolution, nor do they see it as a positive contributor to evolution today.

We have shown before that most of the emphasis on evolution by these writers relates to the mismatch between the ancestral environment and present-day needs. They stress that "in many ways we are stuck with the psychology and drives of our huntergatherer ancestors" (Savulescu and Sandberg 2012, 28). However, being sophisticated authors, Salvulescu and Sandberg argue for enhancement while engaging their critics in a serious manner. In this way, they position themselves against more utopian transhumanists, rejecting forms of necessity and determinism for future enhancements (see also Earp, Sandberg and Savulescu 2014, 6-7). They even recognize that social context is crucial for love and that love doesn't "just happen," but rather involves human freedom and conscious effort, which could be potentialized through the proper administration of hormones (Ibid., 10). Children appear in this scene as one group of those who benefit from balanced experiences of love. There is little mention of the relationship between mothers, allomothers, and infants as a major source of love coming from our evolutionary past, or the abnegation of these actors to allow for the well-being of children.

On the one hand, the importance of play in human evolution receives hardly any attention in transhumanist literature, and sometimes it is downgraded. Bostrom, for example, says, "Play ..., which occurs only in some species and predominantly among juveniles, is mainly a way for the young animal to learn skills that it will need later in life. When emulations can be created as adults, already in possession of a mature 
repertoire of skills, or when knowledge and techniques acquired by one AI [greaterthan-human AI being] can be directly ported into another AI, the need for playful behavior might become less widespread" (Bostrom 2014, 175). Again, the focus is on individual enhancement; the collective character of play is overlooked.

On the other hand, play is at the roots of storytelling (Boyd 2009). Patricia J. Manney (at that time, Chair of the World Transhumanist Association Board of Directors) wrote a paper about the role of storytelling in empathy (Manney 2008), in which she defends the role of empathy without waiting for technological fixes in a technology-driven world, where narcissism is on the rise. She advances storytelling as the way to awake our sense of otherness (e.g., between enhanced and natural individuals) and so to increase empathy. However, this paper did not receive much attention in the literature.

\section{Personal identity in the present and in the future}

Finally, let us point to one more issue in transhumanist literature, regarding human identity. Transhumanists usually uphold continuity between present personal identity and future embodiments of one's post-human condition, in whatever material basis it may occur. According to leading transhumanist Natasha Vita-More, "crucially, in emitting or transferring personhood onto and into numerous substrates and platforms, we must safeguard the continuity of identity. ... Of critical concern is what holds our thoughts together, preventing a fracturing of the mind" (Vita-More 2014, 245). She concludes by saying, "All in all, biology has outperformed its own benchmarks, if not through evolution then though neuropharmaceuticals and internal and external enhancement devices and appendages" (Ibid., 246).

How can a person achieve creativity and permanence? Traditional ways to do so are well known; new generations provide some kind of immortality for us, and allow for breakthroughs in human creativity (Townsend 2012, 92). Transhumanists think this is unsatisfactory. Instead of relying on our posterity, we could be more creative and permanent through proper enhancement of ourselves. This may be achieved both by tinkering with biological traits linked to creativity (Young 2006) and by assuring that the aging process does not compromise it: "A longer healthspan is more valuable when one has the cognitive capacity to find virtually inexhaustible sources of meaning in creative endeavors and intellectual growth" (Bostrom 2008, 135).

Therefore, for many transhumanists the experience of birthing and parenthood 
seem to be of secondary concern (unless it happens in the context of assisted reproduction, "designer babies," and freedom of choice), especially for those seeking ultra-extended longevity (Pellissier 2013, position 4108).

\section{Our die-hard biological heritage}

In the preceding section, we engaged in a panoramic view of transhumanist thought on evolution and the role of childrearing. In this final section, we chose seven key transhumanist ideas, drawn from our discussion above, and we will briefly show how they are impacted by the data relating to the effect of natality on human evolution. In like manner, we will suggest how hard it is for the biological substratum of ours to die.

\section{Mismatched ancestral environment - contemporary world}

As has been seen above, when confronting biological evolution, transhumanists usually adopt two strategies. First, they suggest that evolution is a piece of "bad engineering," and that we, with a better knowledge of the processes of natural selection, may improve on nature's work. Second, they acknowledge that perhaps our biological makeup was optimal in an ancestral environment, but that many traits are now detrimental to our modern way of life.

In accordance with what we saw in the first two sections, both strategies are found wanting. The first strategy captures only part of what evolution is all about, ignoring trade-offs that improved well-being in ancestral conditions. For humans, these tradeoffs led to the creation of a strong cultural community, mainly centered on cooperative breeding.

The second suggestion ignores the effect of ancestral environments on making humans very resilient, with the capability of adapting, through a suitable coevolution, to novel environments. However, it is possible to argue that, instead of trying to deal with the "mismatch" by freeing us from biological constraints, it would be better to adjust modern ways of life in accordance to lessons drawn from evolutionary biology. Indeed, our ancestors developed culture in order to compensate for genetic shortcomings, but ended up contributing to genetic evolution itself.

As psychologist Ad Bergsma has argued, in criticism of enhancement projections: "The human species evolved in the African savanna . . but this does not make it 
impossible to enjoy life in modern industrial societies. ... Our biological make up will probably allow us to live happily in a future information society as well" (Bergsma 2000, 403). He finally concludes that "as long as progress does not push us to the limits of our adaptive potential, the best option is not to redesign our brains, but to change the world we live in" (Ibid., 414).

Bergsma's argument is not an apology for stopping scientific and technological development that yields both healing and some kind of enhancement; it rather corresponds to the remarks on synthetic biology that we saw in the second section, regarding the limits of gene-centered technology.

\section{Mothers, babies and birth canals}

Transhumanists' negative view of human evolution carries little regard for motherhood as a major component in it. Therefore, by not paying attention to processes of birth and childcare in the past, transhumanists may see little use for them in the near future. Our contention, however, is that the well-being of present and future humans, as well as "what we value" (Bostrom), is strongly connected to these processes, which are associated with hormones and the mammalian brain.

Indeed, Bjorklund (2007), as well as Susan Pinker and Trevathan, have demonstrated that some current trends in birthing and childrearing, too reliant on medical intervention, have partially backlashed, insofar as well-winnowed behaviors enabled by past gene-culture coevolution were considered outdated. However, these behaviors still are, and will be, essential for informing what creative humans are all about. According to Christine Overall, “Although one can't really know what it means to be a parent until one is already embarked upon it, having a child is an opportunity for self-transformation. Perhaps it is the very unknown nature of parenthood itself that has the potential to make it transformative" (Overall 2012, 219). There are many ways to accomplish self-realization other than parenthood, but I would argue that having children and caring for them is, and it will be, the most common and democratic way of improving humanity.

\section{Positive emotions only?}

As we have tried to show, not much of the transhumanist literature deals directly 
with the evolutionary background of human emotions. However, if nature does not care, and evolution does not lead to optimization, how would it be possible to use its mechanisms to foster only good emotional traits? This question is advanced by ethicist Felicitas Kraemer. In her analysis of Bostrom's arguments, she highlights “the fact that emotions are embedded in a complex context and that they cannot simply be increased without bringing about unforeseeable effects" (Kraemer 2012, 437). Therefore, if she is right (and the analysis of our first section lends some support for her argument), in order to improve positive emotions we have to bear with the accompanying negative emotions, otherwise any actual accomplishment will be impeded. Even those emotions that everybody agrees are positive in humans have a fundamental ambiguity; if the context and the intent changes, these emotions may do more harm than good.

This ambiguity of emotional experience is related to what Kapur et al (2011, xii) have called "the paradoxical brain" ("Particularly in the realm of clinical science, paradoxes may be evident when what normally hinders may help, and what normally helps may hinder." [Ibid., 3]) In other words, an effective enhancement of the brain, in order to reach its goals, cannot be unaware of the brain's paradoxical nature. This is the flipside of the "sloppy engineering" of our evolution, indicating once again that negative and positive traits come hand in hand.

\section{Happiness, yes. Suffering, no.}

As transhumanists generally think, "the good life is the pain-free life," (Bastian), at least for involuntary pain. However, psychologist Nicholas Baylis (2009), at Cambridge University, argues that well-being, not happiness, should be the target of our efforts for enhancement. A balance of pleasure and pain is crucial for our well-being. Some transhumanists (cf. the work of Savulescu and others), as we have seen, acknowledge this, but they are suspicious of present means to accomplish well-being. Natural selection is not about happiness, but fitness for reproduction. Yet, the same processes yielded as trade-offs the means to achieve happiness, and parenthood has been a major source of happiness.

The emotion called "love" has many meanings. Love involves dramatic choices as seen in Hrdy's description of the modern world's expectations of motherhood: "Evolutionists like Trivers and Bolwby appeared to impose on women painful choices no man need ever make: her aspirations versus her infant's well-being. Vocation or 
reproduction" (Hrdy 2000, 490). These choices became more poignant in a competitive world like ours, where a career is highly prized.

All the vicissitude and abnegation around having a baby and rearing it, which has been constant throughout our evolution up to now, is largely absent in transhumanist discourse. As we can draw from what has been argued above, all the happiness we can get from parenthood comes in the midst of pain and suffering, even when many instances of the latter can be removed by technological means.

\section{Babies, a problem or an opportunity?}

As suggested above, the ideal picture in transhumanism is of a generic human or an empowered male, so women's experiences and specific emotions are seldom taken into account. However, these experiences indicate that the suffering brought by birth pangs, though viewed as senseless by hedonistic and utilitarian considerations, may also bring about what is distinctive and sublime in the human species: the possibility of love.

Adding to what has been said by Trevathan and others, Australian physician Sarah Buckley argues that the exquisite mixture of pain and pleasure during childbirth is in the end better for the mother and the baby (Buckley 2003, 264-65), even though this goes against some current Western stereotypes. She also makes the somewhat controversial claim that undisturbed birth, because of the optimal equilibrium which was acquired by our lengthy evolutionary process, is preferable to childbirth through medical interventions, including anesthetics and induction.

In sum, designer babies may require sophisticated technology and close medical observation, but this goes against contemporary trends of parents wishing to have their offspring in a more natural way. As Trevathan puts it, judging the sophisticated technology around childbirth: "a crying baby...'is no longer merely a being to be loved, but a problem to be solved"' $(2010,154){ }^{6}$

\section{Continuity, permanence, persistence and new generations}

Robotics specialist Illah R. Nourbakhsh, commenting on Pearce's radical view, says, "Instead of producing children as our legacy, we will modify our own selves, leaving natural selection in the dust by changing our personal genetic makeup in the most extremely personal form of creative hacking imaginable" (Nourbakhsh 2012, 237). This move would certainly require a break with our present identity. For moderate 
transhumanists this is unacceptable (see Powell, Kahane, and Savulescu 2012, 446).

However it may be defined, if personal identity should be maintained at any cost, is it possible to sever it from these biological bonds (Hopkins, 2015)? If this personal identity is built on old templates from our evolutionary past, is it possible to get rid of the scars of this past?

Continuity in these future scenarios takes place between a conscious adult and his or her post-human form. Children, again, take no part in it. However, as so much of our psychology is connected with procreation and sociality, it is once more our contention that efforts towards improving humanity that do not incorporate birth and childcare cannot lead to a successful enhancement.

\section{What role is there for children in a Brave New World?}

Transhumanists may resent the contention that they are not concerned with the well-being of children. In their view, allowing for the best parental decision, designer children are liable to receive better care than traditional ones, through strict control of their biological profile and educational contexts. However is such a degree of control, according to the present paradigms, truly in children's best interests? Does not this control add up to some contemporary trends that allow for fewer and fewer births in the developed countries? After all, according to many commentators, children impede women's success in the job market (as described, e.g., by Tyler [2009]).

We have already seen, when quoting Bostrom $(2014,175)$, that children's behaviors are not acknowledged in proposals of enhancement. But we have also seen that the ways we are born and reared and the long period that comprises childhood and adolescence have been a pre-condition in the past for maintaining and improving intelligence (Rossano 2010, 147; Bjorklund 2006; Relethford 2010, 121; Keller, Poortinga and Schölmerich 2002). Having a child is a transformative experience (Overall [2012], Paul [2015]), and this is the flipside of the drama of contemporary mothers. Since we do not know in what direction this transformation is going to happen, novelty then becomes possible.

Our being human does rely much on childhood, and even those who decide to remain childless still carry, in varying ways, the biological inclination towards reproduction, or at least the concern to help the offspring of others. Any personal identity, regardless of the variety, cannot break free from these constraints. How could a 
post-human extend and overcome a human being if this most basic aspect of the human is ignored?

Our contention, therefore, has been that we are still connected with our biological past, particularly in the case of begetting new generations, because the history of human evolution is so tightly related to child rearing. The difficulties associated with childbirth, extensive care with communal support, face-to-face interaction, storytelling, and rites of passage seem to be adaptive, at least in biocultural evolution, and so they seem to be deeply ingrained in our brains. The drive for natality as a source of novelty in the human timeline, having such strong ties to our evolutionary past, cannot and should not be uprooted from this past by the use of technological intervention.

\section{Conclusion}

Throughout this paper, we gathered elements to answer two demanding questions. First, what does human evolution indicate to us about the role, if any, of new births and child rearing in creating human identity? Second, if having children was adaptive in the past, will it be necessarily so in the future?

For this purpose, we first screened the literature about the evolution of human birth, emphasizing the dramatic character of this process, marked by much suffering, while at the same time being a source of cooperation and increased intelligence. Indeed there are many trade-offs that place human birth (in a continuous development since early hominids) at the origins of many traits that we are proud of and willing to enhance through suitable means.

Next, we have shown that more concerned transhumanists claim that they consider natural selection principles in their proposals, but they overlook the role of birthing and childrearing. They speak, rather, in terms of biological constraints, which are only detrimental to human futures. Therefore, in this view, the drive to bear and nourish children in the natural way and in a communal setting, may have had adaptive value in the past, but is now usually a hindrance to personal achievement. Moreover, they also overlook the bittersweet experience of parenthood, the obstinate character of the new beings which leads to the loss of control over our plans and dreams, and yet which comes alongside a feeling of giftedness.

Paramount among the traits that transhumanists wish to improve is our intelligence and creativity. However, as we have seen for human beings, these traits are 
so intrinsically connected to the whole process of begetting and caring for new generations that the likeliest scenario is one of decreased novelty. Other goals, related to transhumanist catchwords such as "longer," "stronger," "smarter," "happier," "fairer," may not match expectations.

It is true that transhumanists who are more closely related to the academy have a more nuanced argument in order to respond to their critics, but one may raise the question whether it is still possible to speak of enhancement with so many nuances in the argument. Perhaps these proposals are just a different, more technologically savvy, approach to current problems. But this would be a matter for another research project.

Philosophical considerations are now in order. Humans are often able to reach the highest levels of happiness, and be ennobled by it, through free decisions made in unfavorable conditions. And true happiness, according to many thinkers across many cultures, is reached through pursuing values and virtues, commitment and sacrifice, and not by technologies that take the burden out of our decisions. ${ }^{7}$ Needless to say, this does not mean that technological advances to alleviate human suffering and improvement of our condition should stop. It only means that the transition to posthumanity may exact an unacceptable toll on many human emotions, in particular those associated with natality.

\section{NOTES}

\footnotetext{
1 "Transhumanism and the Fate of Natality: An Introduction" (Zygon, vol. 48, no. 4 [December 2013]: 916-35). As for Arendt's meaning of natality, let us quote her The Human Condition: "the new beginning inherent in birth can make itself felt in the world only because the newcomer possesses the capacity of beginning something anew, that is, of acting." (Arendt 1998 [1958], 9)

2 This association is important for our discussion of transhumanism below.

${ }^{3}$ This is a technical term much used by Sarh B. Hrdy, meaning those females who act as surrogate mothers and do not belong to the near family. When males are taken into account, we have "alloparents."

4 "Epigenesis can be defined as 'an emergent process by which an organism's structure and function change from relatively undifferentiated states to increasingly specialized, differentiated forms throughout ontogeny' (Miller, 1998, p. 105). From this perspective, one cannot partition biologic from environmental effects on the organisms, for genes, hormones, neurons, maternal care, and the physical and social environment all contribute dynamically to produce behavior." (Bjorklund 2006, 215-216)

${ }^{5}$ See, e.g., the entire issue of Philosophy of Technology, 25 (4), 2012. However, these essays are not directly relevant to our discussion, except the introductory one by Powell, Kahane and Savulescu, for more general purposes.

${ }_{7}^{6}$ This quote in single quotations marks is from the NYT (December 12, 2002), a piece by Bruce Gierson. ${ }^{7}$ Many transhumanists may protest against this claim, insofar as they adopt a liberal-minded philosophy in which any individual is free to decide on his or her life. However, the most important decisions in our lives involve an emotional toll that leads to suffering, precisely what transhumanists seek to overcome.
} 


\section{REFERENCES}

Alcorta, Candace S. and Richard Sosis. 2005. "Ritual, Emotion, and Sacred Symbols. The Evolution of Religion as an Adaptive Complex." Human Nature, Winter, Vol. 16, No. 4: 323-359.

Arendt, Hannah. [1998] 1958. The Human Condition. $2^{\text {nd }}$ ed. Chicago: University of Chicago Press.

Askland, Andrew. 2011. "The Misnomer of Transhumanism as Directed Evolution.” International Journal of Emerging Technologies and Society. Vol. 9, No. 1: 7178.

Bard, Kim A. 2009. "Social Cognition: Evolutionary History of Emotional Engagements with Infants.” Current Biology, Vol. 19 No. 20: R941-943.

Bastian, Bock, Jolanda Jetten, Matthew J. Hornsey and Siri Leknes. 2014. "The Positive Consequences of Pain: A Biopsychosocial Approach.” Personality and Social Psychology Review, August, vol. 18 no. 3: 256-279.

Baylis, Nick. 2009. "What is Your Mission in Life? Why Being Happy should Not be Your Priority." In Unnatural Selection: The Challenges of Engineering Tomorrow's People. Ed. Peter Healy and Steve Rayner, 167-174. London: Earthscan.

Bergsma, Ad. 2000. "Transhumanism and the Wisdom of Old Genes: Is Neurotechnology a Source of Future Happiness?” Journal of Happiness Studies 1: 401-417.

Bjorklund, David F. 2006. "Mother knows best: Epigenetic inheritance, maternal effects, and the evolution of human intelligence." Developmental Review 26: $213-$ 242.

2007. Why youth is not wasted on the young: immaturity in human development. Oxford: Blackwell Publishing.

Bjorklund, David F., and Anthony D. Pellegrini. 2000. "Child Development and Evolutionary Psychology.” Child Development, November/December 2000, 71/6:1687-1708.

Bostrom, Nick . 2008. "Why I Want to be a Posthuman When I Grow Up." In Medical Enhancement and Posthumanity, ed. Bert Gordijn and Ruth Chadwick, 107-137. 
Heildelberg: Springer.

2014. Superintelligence: Paths, Dangers, Strategies. Oxford: Oxford University Press.

Bostrom, Nick, and Rebecca Roache. 2008. "Ethical Issues in Human Enhancement."

As available in http://www.nickbostrom.com/ethics/human-enhancement.pdf.

Retrieved 12/22/2014.

Bostrom, Nick, and Anders Sandberg. 2008. "The Wisdom of Nature: An Evolutionary

Heuristic for Human Enhancement.” In Human Enhancement, ed. Julian

Savulescu and Nick Bostrom, 375-416. Oxford: Oxford University Press.

Boudry, Maarten, and Massimo Pigliucci. 2013. "The mismeasure of machine:

Synthetic biology and the trouble with engineering metaphors." Studies in History and Philosophy of Biological and Biomedical Sciences 44: 660-668.

Boyd, Brian. 2009. On the origin of stories: evolution, cognition, and fiction.

Cambridge, Mass.: Belknap Press, 2009.

Buckley, Sarah J. 2003. "Undisturbed Birth: Nature's Blueprint for Ease and Ecstasy." Journal of Prenatal and Perinatal Psychology and Health, 17(4), Summer: 26188.

Caffrey, Anna. 2014. "Experiences of Pleasurable Childbirth: Uncovering a Blind Spot in Anthropology.” Popular Anthropology Magazine, Vol. 5 No. 1: 17-27.

Decety, Jean. 2011. The Neuroevolution of Empathy. Annals of the New York Academy of Sciences, 1231: 35-45.

De Prycker, Valérie. 2007. "Critical Remarks on Shortcuts to Happiness: The Relevance of Effort and Pain.” Philosophica 79: 57-70.

Douglas, Thomas, et.al. 2010. “Resisting Sparrow's Sexy Reductio: Selection Principles and the Social Good.” American Journal of Bioethics July, 10 (7): 1618.

Douglas Thomas, and Julian Savulescu. 2010. "Synthetic biology and the ethics of knowledge." Journal of Medical Ethics 36:687-693.

Dvorsky, George, and James Hughes. 2008. "Postgenderism: Beyond the Gender Binary." Institute for Ethics and Emerging Technologies, 20 March, 44-57. Available at http://ieet.org/archive/IEET-03-PostGender.pdf. Retrieved in August 08, 2014.

Earp, Brain D, Anders Sandberg and Julian Savulescu. 2012. "Natural Selection, 
Childrearing, and the Ethics of Marriage (and Divorce): Building a Case for the Neuroenhancement of Human Relationships." Journal of Philosophy and Technology, 25:561-587.

Earp, Brian D et.al. 2014. "When is diminishment a form of enhancement? Rethinking the enhancement debate in biomedical ethics." Frontiers in Systems Neuroscience, (February), volume 8, Article 12: 1-8.

Earp, Brian D., Allen Sandberg and Julian Savulescu. 2014. "The Medicalization of Love." Cambridge Quarterly of Healthcare Ethics 0: 1-14.

Eden, Amon H., Johnny H. Sørake, James H. Moor and Eric Steinhart, eds. 2012. The Singularity Hypothesis: A scientific and philosophical assessment. Dordrecht, Berlin: Springer.

Gansel, Carsten. 2012. "Storytelling from the Perspective of Evolutionary Theory." In Gansel and Vanderbeke (2012), 77-109.

Gansel, Carsten, and Vanderbeke, Dirk (eds.). 2012. Telling Stories/Geschichten erzählen Literature and Evolution/Literatur und Evolution. Berlin: Walter De Gruyter.

Gottschall, Jonathan. 2012. The Storytelling Animal: How Stories make us Human. NewYork: Houghton Mifflin Harcourt.

Grinde, Bjørn. 2012. The Biology of Happiness. Dordrecht: Springer Verlag.

Hawkes, Kristen. 2006. "Slow Life Histories and Human Evolution. In The Evolution of Human Life History, ed. Kristen Hawkes and Richard R. Paine, 95-126. Santa Fe: School of American Research Press.

Hewlett, Barry S., Adam H. Boyette. 2012. "Play in Hunter-Gatherers.” In Evolution, Early Experience and Human Development: From Research to Practice and Policy, ed. Darcia Narvaez et.al., 388-393. Oxford: Oxford University Press.

Hope, Tony. 2011. "Cognitive Therapy and Positive Psychology Combined: A Promising Approach to the Enhancement of Happiness." In Enhancing Human Capacities, ed. Julian Savulescu, Ruud ter Meulen and Tony Hope, 230-244. .Oxford: Wiley- Blackwell.

Hopkins, Patrick D. 2015. "A Salvation Paradox for Transhumanism: Saving You versus Saving You." In Religion and transhumanism: the unknown future of human enhancement, ed. Calvin Mercer and Tracy J. Trothen, 71-81. Santa Barbara, CA: Praeger / ABC-CLIO, LLC. 
Hrdy, Sarah B. 2000. Mother Nature: A History of Mothers, Infants, and Natural Selection. New Tor: Random House. .2009. Mothers and Others: The Evolutionary Origins of Mutual Understanding. Cambridge, Mass: Belknap Press.

Hughes, James. 2010. "Contradictions from the Enlightenment Roots of Transhumanism.” Journal of Medicine and Philosophy, 35: 622-640. doi:10.1093/jmp/jhq049.

Kahane, Guy, and Julian Savulescu. 2010. "The Value of Sex in Procreative Reasons." The American Journal of Bioethics, July, Volume 10, Number 7: 22-24.

Kapur, Narinder et.al. 2011. The Paradoxical Brain. Cambridge: Cambridge University Press.

Karlsdottir, Sigfridur Inga, Sigridur Halldorsdottir, and Ingela Lundgren. 2014. "The third paradigm in labour pain preparation and management: the childbearing woman's paradigm.” Scandinavian Journal of Caring Sciences, 28: 315-327. Doi $10.1111 /$ scs.12061.

Katz, Bruce F. 2008. Neuroengineering the future: virtual minds and the creation of immortality. Hingham, Ma: Infinity Science Press.

Keller, Heidi, Ype H. Poortinga, and Axel Schölmerich, eds. 2002. Between Culture and Biology. Perspectives in Ontogenetic Development. Cambridge: Cambridge University Press.

Kurzweil, Ray. 2005. The Singularity is Near. When Humans Transcend Biology. New York: Viking Press.

Kraemer, Felicitas. 2012. "Some Problems with Genetic Emotional Enhancement." Journal of Value Inquiry 46:435-447.

LaTorra, Michael. 2011. "Transhumanism: Threat or Menace? A response to Andrew

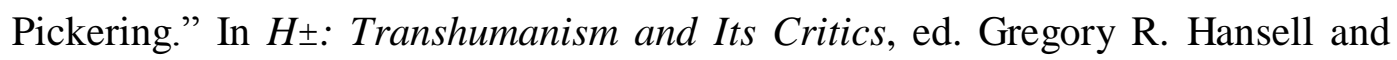
William Grassie, 205-211. Philadelphia: Metanexus Institute.

Lauster, Nathanael, and Graham Allan, eds. 2012. The end of children? Changing trends in childbearing and childhood. Vancouver/Toronto: UBC Press.

Leistle, Bernhard. 2006. "Ritual as Sensory Communication - A Theoretical and Analytical Perspective." In Ritual and Identity: Performative Practices as Effective Transformations of Social Reality, ed. Klaus-Peter Koepping, Bernhard Leistler and Michael Rudolph, 33-74. Münster, Berlin, London: LIT Verlag. 
Leknes, Siri and Irene Tracey. 2008. “A common neurobiology for pain and pleasure.” Nature Reviews Neuroscience, 9, 314-320. . 2010. "Pain and pleasure: Masters of mankind." In Pleasures of the brain: The neural basis of sensory rewards, ed. M. L. Kringelbach \& K. C. Berridge, 320-335. New York, NY: Oxford University Press.

Lewens, Tim. 2013. "From bricolage to BioBricks" ${ }^{\mathrm{TM}}$ : Synthetic biology and rational design." Studies in History and Philosophy of Biological and Biomedical Sciences 44: 641-648.

Manney, Patricia J. 2008. Empathy in the Time of Technology: How Storytelling is the Key to Empathy. Journal of Evolution and Technology Vol. 19 Issue 1 September: 51-61. Available in http://jetpress.org/v19/manney.htm. Retrieved March 13, 2014.

Maul, Armand. 2007. "An evolutionary interpretation of the significance of physical pain experienced by human females: Defloration and childbirth pains." Medical Hypotheses 69: 403-409.

Mellmann, Katja. 2012. "Is Storytelling a Biological Adaptation? Preliminary Thoughts on How to Pose that Question.” In Gansel and Vanderbeke (2012), 30-49.

Melo-Martín, Immaculada. 2008. “Designing People, a Post-Human Future?” In Philosophy and Design From Engineering to Architecture, ed. Pieter Vermaas et.al., 197-207. Dordrecht: Springer.

More, Max. [1999] 2013. “Letter to Mother Nature.” In The transhumanist reader: classical and contemporary essays on the science, technology, and philosophy of the human future, ed. Max More and Natasha Vita-More, 449-450. Oxford: Wiley- Blackwell.

Nesse, Randolph N. 2004. "Natural selection and the elusiveness of happiness." Phil. Trans. R. Soc Overall, Christine. 2012. Why have children? The ethical debate. Cambridge, MA: The MIT. Lond. B 359: 1333-1347.

Nourbakhsh, Illah R. 2012. “On Pearce's 'The Biointelligence Explosion'.” In Eden et.al. (2012), 237-240.

Overall, Christine. 2012. Why have Children? The Ethical Debate. Cambridge, MA: The MIT Press.

Panksepp, Jaak. 2005. “On the Neuro-Evolutionary Nature of Social Pain, Support, and Empathy.” In Pain: New Essays on Its Nature and the Methodology of Its Study, 
ed. Murat Aydede, 367-387. Cambridge, MA: Bradford Book/MIT Press.

Paul, Laurie Ann. 2015. "What you Can't Expect when you're Expecting." Res Philosophica 92:2 (April). Available at http://www.resphilosophica.org/resphil.2015.92.2.1. Retrieved January 2, 2015.

Pellissier, Hank, ed. 2013. Human Destiny is to Eliminate Death. Essays, Rants and Arguments about Immortalism. Thorold, Canada: Center for Transhumanity. Kindle Edition.

Pelissier, Hank and Tereza dal Santo. 2012. "Transhumanists: Who Are They, What Do They Want, Believe And Predict?” Journal of Personal Cyberconsciousness. Vol. 7, Iss. 2:20-29.

Pinker, Susan. 2014. The Village Effect. How Face-to-Face Contact can make us Healthier and Happier. London: Atlantic Books.

Powell, Russell. 2012. "The Future of Human Evolution.” British Journal for the Philosophy of Science 63: 145-175.

Powell, Russell and Allen Buchanan. 2011. "Breaking Evolution's Chains: The Prospect of Deliberate Genetic Modification in Humans." Journal of Medicine and Philosophy, 36: 6-27.

Powell, Russell, Guy Kahane and Julian Savulescu. 2012. "Evolution, Genetic Engineering, and Human Enhancement." Journal of Philosophy and Technology. 25:439-458.

Relethford, John H. 2010. The Human Species: An Introduction to Biological Anthropology. 8th edition. New York: McGraw-Hill.

Rosenberg, Karen, Wenda Trevathan. 2002. "Birth, obstetrics and human evolution." BJOG: an International Journal of Obstetrics and Gynaecology, November, Vol. 109: 1199-1206.

Rossano, Matt J. 2009. "Ritual Behavior and the Origins of Modern Cognition." Cambridge Archaeological Journal, 19/2 (June): 243-256. . 2010. "How Our Ancestors Raised Children to Think as Modern Humans." Biological Theory, vol. 5, no. 2:142-153.

Savulescu, Julian, and Guy Kahane. 2009. "The Moral Obligation to Create Children with the Best Chance of the Best Life.” Bioethics. Volume 23 Number 5: 274290.

Savulescu, Julian, and Anders Sandberg. 2008. "Neuroenhancement of Love and 
Marriage: The Chemicals Between Us.” Neuroethics, 1:31-44.

Savulescu, Julian, and Anders Sandberg. 2012. "Engineering Love.” New Scientist, 5/12, Vol. 214 Issue 2864: 28-29.

Scalise Sugiyama, Michelle. 2001. Narrative Theory and Function: Why Evolution Matters. Philosophy and Literature, Volume 25, Number 2, October: 233-250. . 2011. The forager oral tradition and the evolution of prolonged Juvenility." Frontiers in Psychology August, Volume 2, Article 133: 1-19.

Small, Meredith. 1997. “Our Babies, ourselves.” Natural History, vol. 106, 9 (October): 42-51.

Spezio, Michael L. 2011. "Human or Vulcan? Theological Considerations of Emotional Control Enhancement." In Transhumanism and Transcendence: Christian Hope in an Age of Technological Enhancement, ed. Ronald Cole-Turner, 145-62. Washington: Georgetown University Press.

Townsend, Nicholas W. "Parenthood, Immortality, and the End of Childhood." In Lauster and Allan (2012), 92-104.

Trevathan, Wenda R. Ancient Bodies, Modern Lives: How Evolution Has Shaped Women's Health. Oxford: Oxford University Press, 2010.

Trevathan, Wenda R. and James J. Mckenna. 2003. "Evolutionary Environments of Human Birth and Infancy: Insights to Apply to Contemporary Life.” In The manner born: birth rites in cross-cultural perspective, ed. Lauren Dundes, 31-52. Walnut Creek, CA: AltaMira Press.

Tyler, Imogen. 2009. “Birth.” Feminist Review. Volume 93, Issue 1 (November): 1-7.

Vita-More, Natasha. 2014. "Design of Life Expansion and the Human Mind." In Intelligence Unbound: The Future of Uploaded and Machine Minds, ed. Russell Blackford and Damien Broderick, 240-247. Oxford: Wiley-Blackwell.

Wells, Jonathan C.K., Jeremy M. DeSilva, and Jay T. Stock . 2012. “The Obstetric Dilemma: An Ancient Game of Russian Roulette, or a Variable Dilemma Sensitive to Ecology?" Yearbook of Physical Anthropology 55:40-71.

Young, Simon. 2006. Designer Evolution: A Transhumanist Manifesto. Amherst, NY: Prometheus Books.

Zuk, Marlene. 2013. Paleofantasy: What Evolution Really Tells Us about Sex, Diet, and How We Live. New York: W.W Norton. 